\title{
Surface evolution during crystalline silicon film growth by low-temperature hot-wire chemical vapor deposition on silicon substrates
}

\author{
Christine Esber Richardson,* Young-Bae Park, and Harry A. Atwater \\ Thomas J. Watson Laboratory of Applied Physics, California Institute of Technology, Pasadena, California 91125-9500, USA
}

(Received 2 November 2005; published 23 June 2006)

\begin{abstract}
We investigate the low-temperature growth of crystalline thin silicon films: epitaxial, twinned, and polycrystalline, by hot-wire chemical vapor deposition (HWCVD). Using Raman spectroscopy, spectroscopic ellipsometry, and atomic force microscopy, we find the relationship between surface roughness evolution and (i) the substrate temperature $\left(230-350{ }^{\circ} \mathrm{C}\right)$ and (ii) the hydrogen dilution ratio $\left(\mathrm{H}_{2} / \mathrm{SiH}_{4}=0-480\right)$. The absolute silicon film thickness for fully crystalline films is found to be the most important parameter in determining surface roughness, hydrogen being the second most important. Higher hydrogen dilution increases the surface roughness as expected. However, surface roughness increases with increasing substrate-temperature, in contrast to previous studies of crystalline Si growth. We suggest that the temperature-dependent roughness evolution is due to the role of hydrogen during the HWCVD process, which in this high hydrogen dilution regime allows for epitaxial growth on the rms roughest films through a kinetic growth regime of shadow-dominated etch and desorption and redeposition of growth species.
\end{abstract}

DOI: 10.1103/PhysRevB.73.245328

PACS number(s): 68.55.- a, 81.15.Kk, 68.37.- d

\section{INTRODUCTION}

The properties of thin films can vary substantially depending on growth conditions. The microstructure and surface evolution are especially important because all other properties-optical, electrical, and mechanical-stem from these. Previously, many researchers have reported on the evolution roughness of amorphous $\mathrm{Si}$ films with substrate temperature $^{1,2}$ and with thickness ${ }^{3}$ and of epitaxial films grown by molecular beam epitaxy (MBE), ${ }^{4}$ ion-assisted MBE, ${ }^{5}$ and with hyperthermal Si beams. ${ }^{6}$ In this study, we address the surface evolution of hot-wire chemical vapor deposited (HWCVD) crystalline $\mathrm{Si}$ thin films (epitaxial, twinned epitaxial, and polycrystalline) with temperature, thickness, and hydrogen dilution and discuss the resulting growth regime and structure.

HWCVD is an unusual epitaxial film deposition process in which the critical epitaxial thickness actually increases with decreasing substrate temperature when breakdown is to a polycrystalline phase ${ }^{7,8}$ and down to $380{ }^{\circ} \mathrm{C}$ when breakdown is to a amorphous phase. ${ }^{9}$ In silicon HWCVD, gas precursors are catalytically decomposed by a hot filament and silane is decomposed with $70 \%$ efficiency. ${ }^{10}$ Thus, the substrate temperature can be at a much lower temperature than in MBE or traditional CVD processes, and one can still achieve high-quality films. ${ }^{11}$

We have deliberately focused on high hydrogen dilution conditions that lead to epitaxial growth with polycrystalline breakdown. In Table I, we summarize the conditions from our work and those of other researchers that have led to epitaxial or polycrystalline growth ${ }^{12,13}$ and compare them to conditions that lead to amorphous films ${ }^{12,14}$ or epitaxial breakdown to an amorphous phase ${ }^{9}$ in HWCVD grown films on crystalline Si substrates. Note that the shift from crystalline to amorphous films occurs with increasing silane partial pressure.

The role of hydrogen dilution in thin film $\mathrm{Si}$ chemical vapor deposition is not fully understood. Many studies have shown that hydrogen increases the crystallinity in films regardless of deposition technique. ${ }^{15,16}$ Robertson ${ }^{16}$ concluded that crystallinity originates through a direct solid-state transformation, in $\mu \mathrm{c}-\mathrm{Si}$ deposition, which causes crystalline nuclei to form due to the higher stability of the crystalline phase. Hydrogen is also thought to play a substantial role in low-temperature epitaxy through hydrogen coverage of the growth surface. ${ }^{17}$ In addition, hydrogen dilution plays an important role in the surface evolution of $\mathrm{Si}$ thin films as it increases the roughness of the growing surface in microcrystalline silicon, ${ }^{18}$ in amorphous silicon, ${ }^{19}$ and in epitaxial silicon. ${ }^{20}$

During the last several decades, many theoretical and numerical simulations of vapor deposited surfaces in conditions far away from equilibrium have been investigated using various continuum models. ${ }^{21-24}$ However, experimental results show that the scaling parameters vary from case to case and strongly depend on the growth conditions and methods, even for the same material. Rather than attempt to compare the present experimental results to particular models for surface growth, we develop a scaling analysis of surface evolution during HWCVD to gain insight into the factors that affect surface morphology as substrate temperature and hydrogen dilution are varied and to use these insights, in turn, to deduce general observations about how growth kinetics and structure change with these parameters.

The self-affine scaling nature of a surface during thin film growth was first introduced by Family and Vicsek. ${ }^{25}$ The growing surface can be characterized as either self-affine or self-similar by its fractal dimension and rms roughness, defined at position $r$ and thickness or deposition time $t$ as $\sigma_{r}(M)=\left\{\Sigma_{i}\left[h_{i}-h(M)\right]^{2}\right\}^{1 / 2}$, where $h(M)$ is the mean height. This roughness and the correlation between points can be described following Constantoudis et $a .^{26}$ by the heightheight correlation function $G(r)$ defined at $r=m^{*} d$ by the function 
TABLE I. Deposition parameter comparison for HWCVD grown films on crystalline Si substrates.

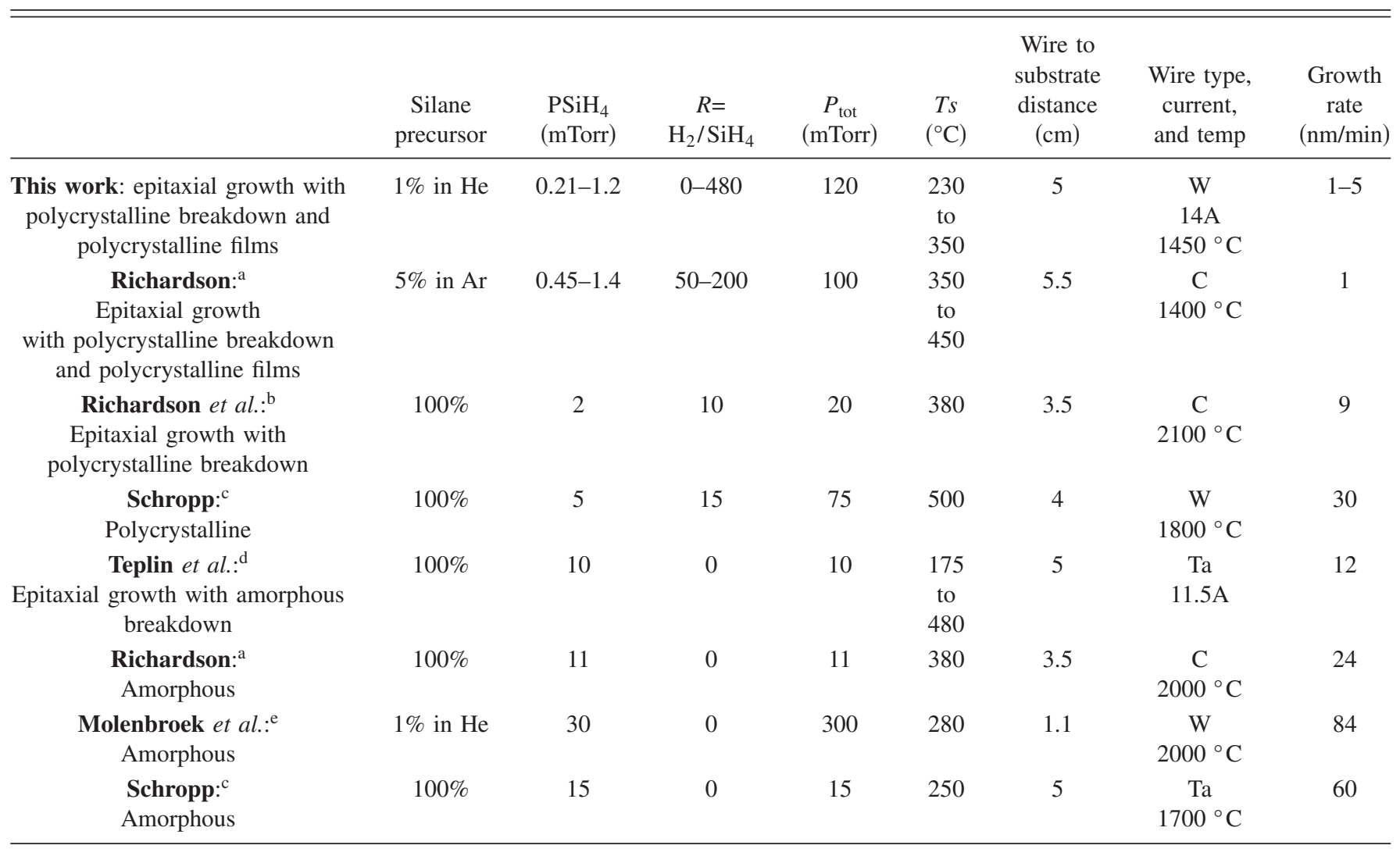

Reference 51 .

${ }^{b}$ Reference 13 .

'Reference 12 .

${ }^{\mathrm{d}}$ Reference 9.

${ }^{\mathrm{e}}$ Reference 14 .

$$
G(m d)=\left[\frac{1}{N-m} \sum_{i=1}^{N-m}\left(\delta_{i+m}-\delta_{m}\right)^{2}\right]^{1 / 2}
$$

where $d$ is the distance between two neighboring points. This equation examines the correlations between the distances $\delta_{i}$ $=\delta\left(y_{i}\right)$ at different positions along the scan direction $y_{i}$, $i=1, \ldots, N$, and $N$ is the total number of equidistant points on $y .^{26}$

In our study, correlation data from atomic force microscopy (AFM) was obtained for a $10 \mu \mathrm{m} \times 10 \mu \mathrm{m}$ scanning size window, unless otherwise noted. Morphologies such as ours have been successfully described in terms of the selfaffine scaling model given by $G(r) \sim r^{\alpha}$, where $\alpha$ is the static scaling coefficient (or Hurst parameter). ${ }^{2,26}$ Self-affine means that the surface remains statistically the same when it is stretched anisotropically in different directions. ${ }^{26}$ At long length scales, the height-height correlation function $G(r)$ approaches the value $\sqrt{2 \sigma}$. The correlation length $\xi$ is defined at

$$
G(\xi)=\sqrt{\left(1-\frac{1}{e}\right)} \sqrt{2} \sigma .
$$

At length scales much greater than $\xi, \sigma_{\text {sat }} \sim t^{\beta}$, where $\beta$ is known as the dynamic scaling coefficient.
In this study, we investigate the evolution of the surface roughness for HWCVD grown crystalline Si thin films: epitaxial, twinned, and polycrystalline, which are of increasing importance to the photovoltaic and semiconductor industries. In this paper, we specifically consider the influence of substrate temperature and hydrogen dilution on the surface morphology and structure of the Si thin films.

\section{EXPERIMENTAL DETAILS}

Crystalline silicon thin films were grown on $\mathrm{Si}(100)$ substrates by hot-wire chemical vapor deposition (HWCVD). The dilution ratio of $\mathrm{H}_{2}$ to $\mathrm{SiH}_{4}$ was varied from 0 to 480 by varying the $\mathrm{H}_{2}$ flow rate with a mixture of $1 \% \mathrm{SiH}_{4}$ in $\mathrm{He}$. Total pressure ranged from 75 to 120 mTorr. Two tungsten wires with diameters of $0.5 \mathrm{~mm}$ were positioned between 3.5 and $5 \mathrm{~cm}$ from the substrate for a growth rate of $\sim 1 \AA / \mathrm{s}$. The wire temperature was set to $1350-1550{ }^{\circ} \mathrm{C}$, as measured by optical pyrometry, and substrate temperatures ranged from $230{ }^{\circ} \mathrm{C}$ to $350{ }^{\circ} \mathrm{C}$.

Before growth, substrates were placed in a UV-ozone cleaning system for $10 \mathrm{~min}$ and then briefly immersed in HF. Once in the chamber, the substrates were heated by the substrate heater and by the radiant heat from the wires for 

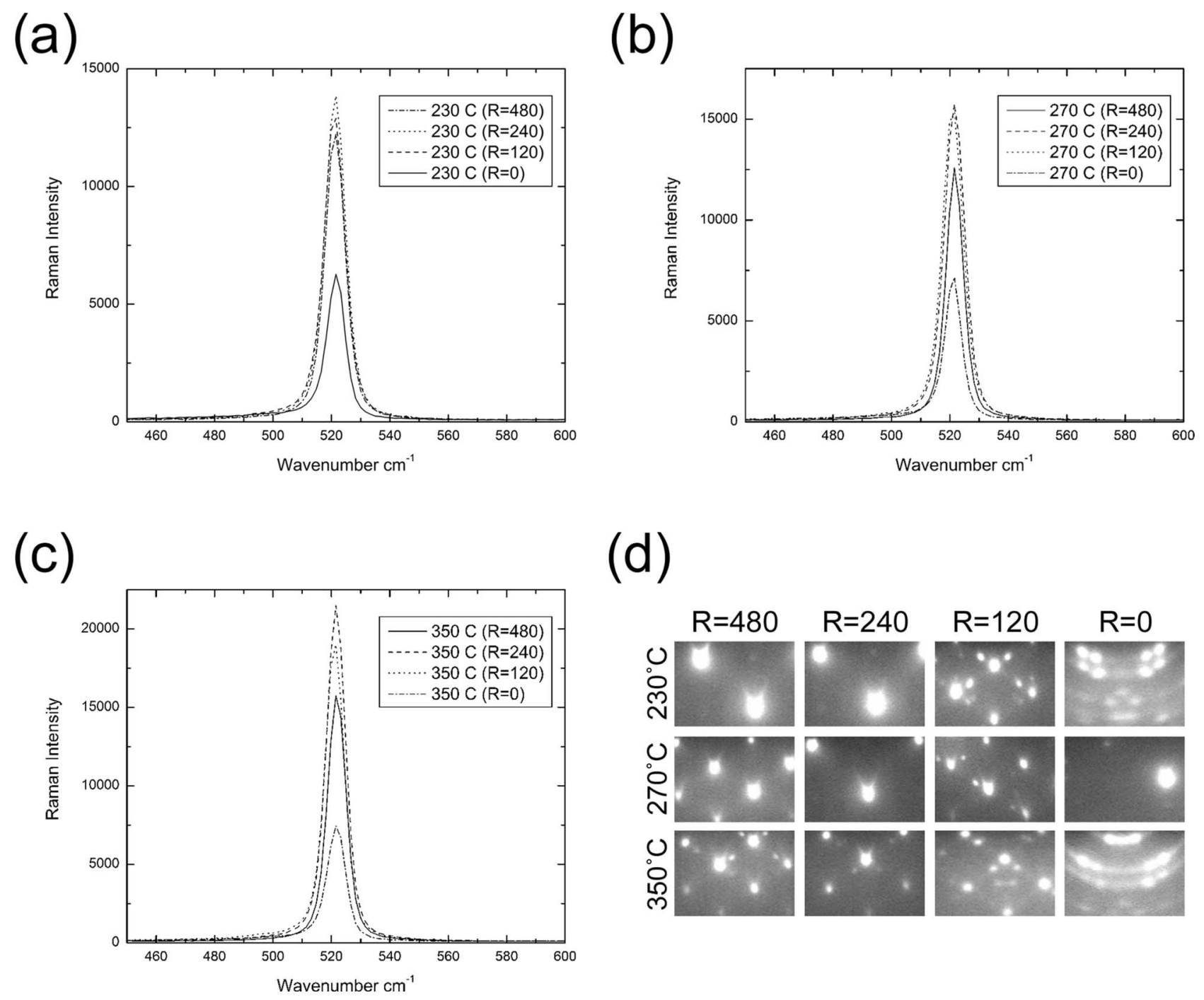

(d)

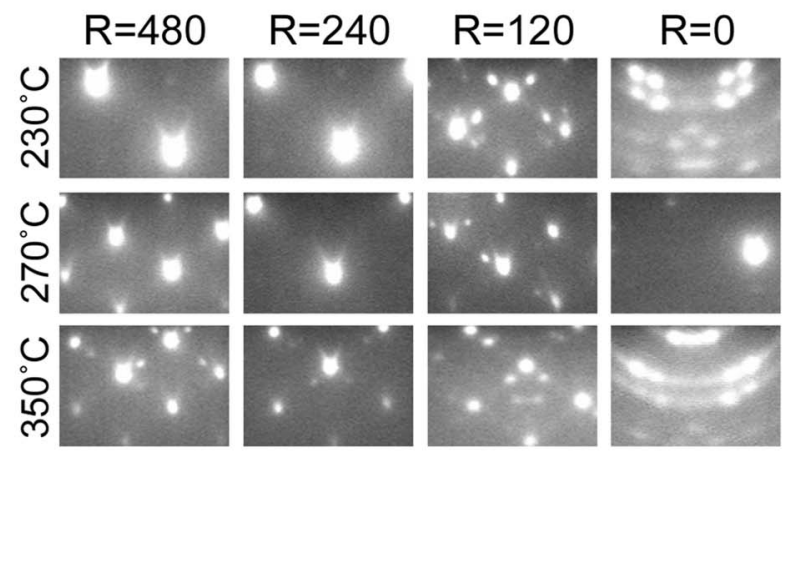

FIG. 1. Raman spectra of thin films on silicon grown at substrate temperatures of (a) $230{ }^{\circ} \mathrm{C}$, (b) $270{ }^{\circ} \mathrm{C}$, and (c) $350{ }^{\circ} \mathrm{C}$. (d). (b) RHEED patterns of HWCVD grown Si films at various substrate temperatures vs hydrogen dilution

30 min to remove any residual hydrocarbons and to bring the wafers up to growth temperature. The substrate temperature was calibrated with a SensArray thermocouple wafer under vacuum, with the wires set at the growth temperature, and has an error of $\pm 50{ }^{\circ} \mathrm{C}$ due to the calibration of the wires. Films with thicknesses in the range of $100 \mathrm{~nm}$ to $6.8 \mu \mathrm{m}$ were grown.

AFM measurements were made on each sample over an appropriate size widow $(40,10$, or $5 \mu \mathrm{m})$ and then analyzed for scaling behavior using a Matlab code expanding the arguments of Constantoudis et al. ${ }^{26}$ into two-dimensions by averaging the height-height correlation functions in the $x$ and $y$ directions. Surface morphology was also investigated by scanning electron microscopy (SEM) to complement the AFM measurements. In order to study the crystallinity of the films, Raman spectra were collected using $514.5 \mathrm{~nm}$ excitation and reflection high energy electron diffraction (RHEED) measurements were performed to characterize the crystallographic structure of the film surface.

\section{RESULTS}

\section{A. Thin film structure and crystallinity}

Unlike other reports of the effect of hydrogen dilution on crystallinity, ${ }^{15}$ we do not observe a change in crystalline fraction with $\mathrm{H}$ dilution [Fig. 1(a)-1(c)], but there is a change in structure from epitaxial to twinned to polycrystalline $\mathrm{Si}$ with decreasing $\mathrm{H}$ fraction [Fig. 1(d)]. All of the samples are fully crystalline as measured by Raman spectroscopy with crystalline silicon peaks at $521.5 \mathrm{~cm}^{-1}$. Despite an apparently porous structure as seen in Fig. 2 for $\mathrm{H}_{2} / \mathrm{SiH}_{4}$ ratio, $R$ $=120-240$, we find no detectable $\mathrm{SiO}_{2}$ fraction as indicated by the absence of $\mathrm{SiO}_{2}$ peaks at 465 and $800 \mathrm{~cm}^{-1}$ during the Raman measurements taken 70 days after deposition with storage in an air ambient. The lack of an internal oxidized surface indicates that these films do not show the instabilities associated with some reports of microcrystalline $\mathrm{Si}^{27}$ This is likely due to the large grain sizes in the polycrystalline films and a small fraction of networked porosity. 


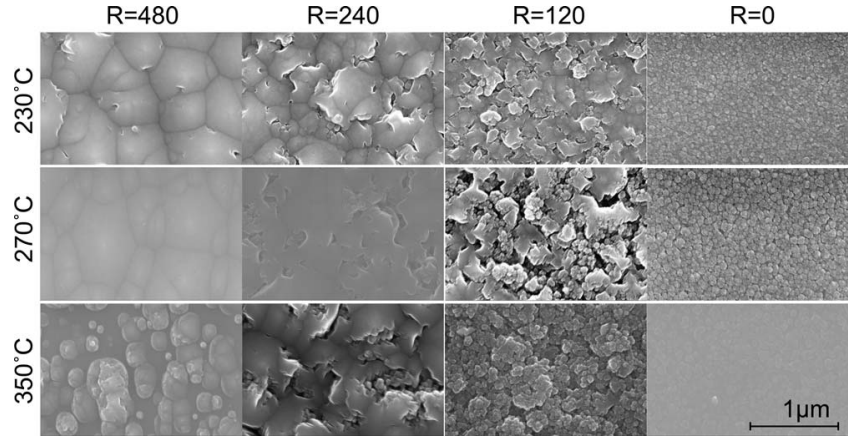

FIG. 2. Scanning electron microscopy images of HWCVD grown $\mathrm{Si}$ films at various substrate temperatures vs hydrogen dilution at $50 \mathrm{kX}$ magnification. Images correspond to the RHEED patterns in Fig. 1 and the atomic force micrographs in Fig. 3.

\section{B. Surface roughness and evolution}

AFM and SEM were used for real space imaging of deposited $\mathrm{Si}$ thin films with various $\mathrm{H}_{2} / \mathrm{SiH}_{4}$ ratios $R$ and substrate temperatures as shown in Figs. 2 and 3. If we look at films of average thickness $300 \mathrm{~nm}$ deposited under a pressure of 120 mTorr with a $5 \mathrm{~cm}$ wire to substrate spacing, the rms roughness and lateral correlation length generally increase with substrate temperature at each dilution [Figs. 3(b) and 3(c)]. This is in contrast to results for both crystalline and amorphous Si seen by molecular beam epitaxy ${ }^{20}$ and plasma-enhanced CVD (PECVD) ${ }^{2}$ and is more akin to the increase in surface roughness with increasing substrate temperature seen in HWCVD grown amorphous silicon. ${ }^{28}$ If we assume as in Mason ${ }^{7}$ and Richardson et al. ${ }^{17}$ that $\mathrm{H}$ coverage prevents contaminants, such as $\mathrm{C}$ and $\mathrm{O}$, from depositing onto the surface, but does allow Si to deposit, then at higher substrate temperatures increased hydrogen desorption leads to higher contaminant incorporation, which would increase the surface roughness with increasing substrate temperature. ${ }^{13,17,29}$ Moreover, given that the $\mathrm{H}$ coverage of the $\mathrm{Si}(100)$ surface at high $\mathrm{H}$ dilutions is large and temperature independent below $300{ }^{\circ} \mathrm{C},{ }^{30}$ then as we lower the substrate temperature from $270{ }^{\circ} \mathrm{C}$ to $230{ }^{\circ} \mathrm{C}$, we suggest that film growth becomes surface mobility limited and there is an increase in the film roughness once more.

Consistent with previous results, the roughness at each temperature increases with increasing $\mathrm{H}$ dilution. This could be due to a decrease in $\mathrm{Si}$ surface diffusion due to the lower amount of $\mathrm{H}$ at higher substrate temperature ${ }^{20}$ or could be due to the H-mediated chemical abstraction of surface amorphous species back into the vapor phase causing an increase in the surface roughness. ${ }^{10,31}$ This last point will be discussed in more detail in Sec. IV.

Interestingly, by comparing Fig. 1(d) with Figs. 3(a) and 3 (c), we see that epitaxial growth is possible on the highest rms roughness surfaces under conditions of high hydrogen dilution. Roughness during growth under most conditions is believed to cause epitaxial breakdown., ${ }^{4,32}$ However, under extreme conditions of high hydrogen dilution, as we find in our experiments, the hydrogen actually improves the preferential growth of epitaxial species by removing amorphous adatoms and defects. This hydrogen etching effect increases the roughness of the films, but allows for the evolution of an epitaxial film to remain.

The rms roughness was obtained from the height-height correlation function plots generated using Eq. (1). Each (a)

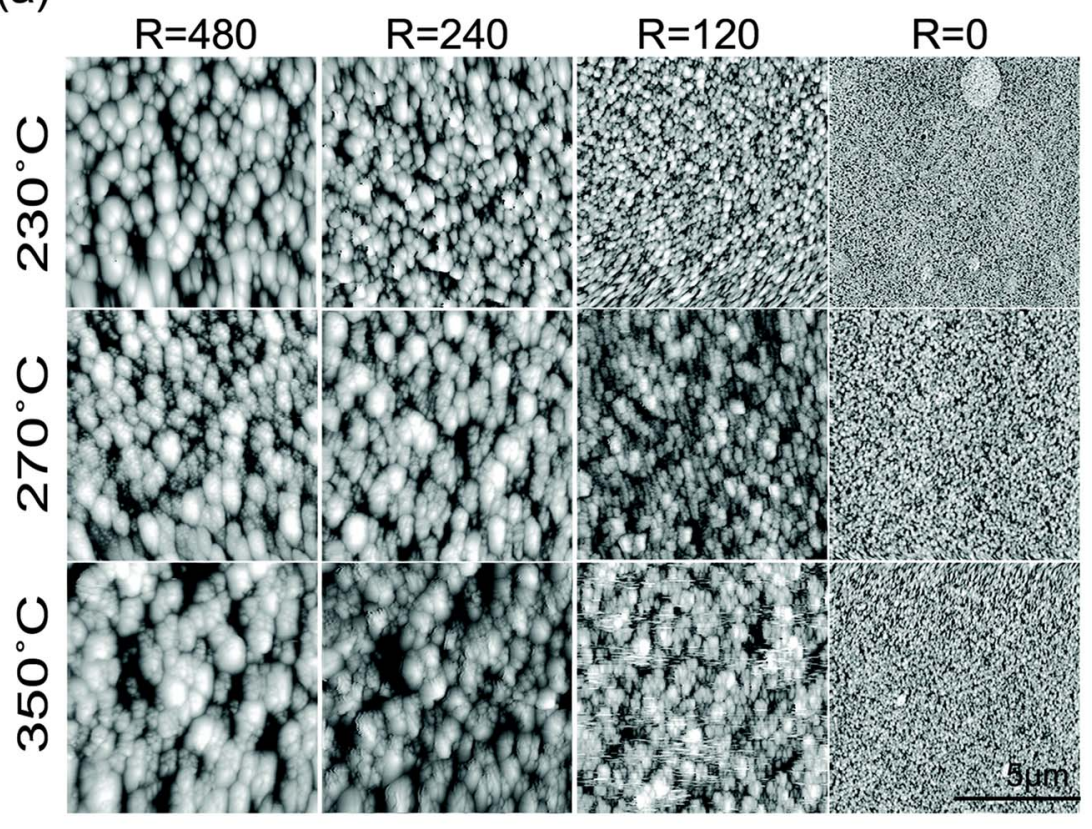

(b)

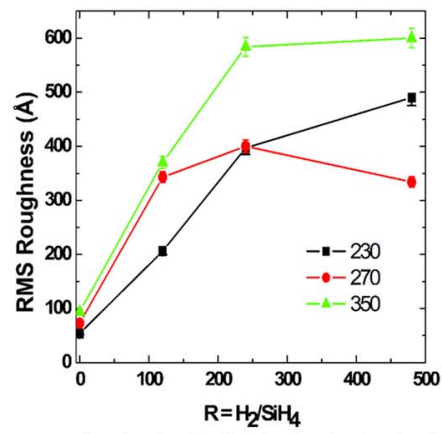

(c)

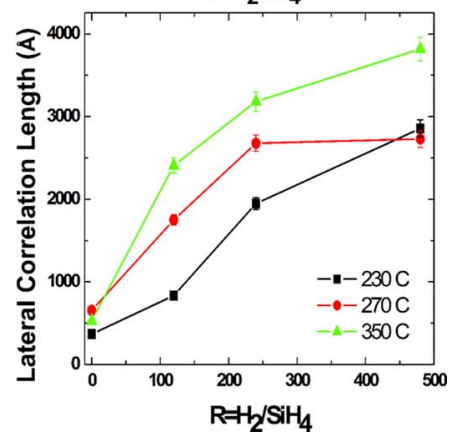

FIG. 3. (Color online) Effect of deposition temperature and $\mathrm{H}_{2} / \mathrm{SiH}_{4}(R)$ ratio on the surface morphology of crystalline Si films. (a) Atomic force micrographs of Si film surfaces taken in contact mode with $10 \times 10 \mu \mathrm{m}^{2}$ area. Micrographs correspond to the SEM images in Fig. 2: (b) rms roughness of films at various substrate temperatures versus hydrogen dilution taken from $10 \mu \mathrm{m} \times 10 \mu \mathrm{m}$ scans and (c) lateral correlation length of the Si films. 

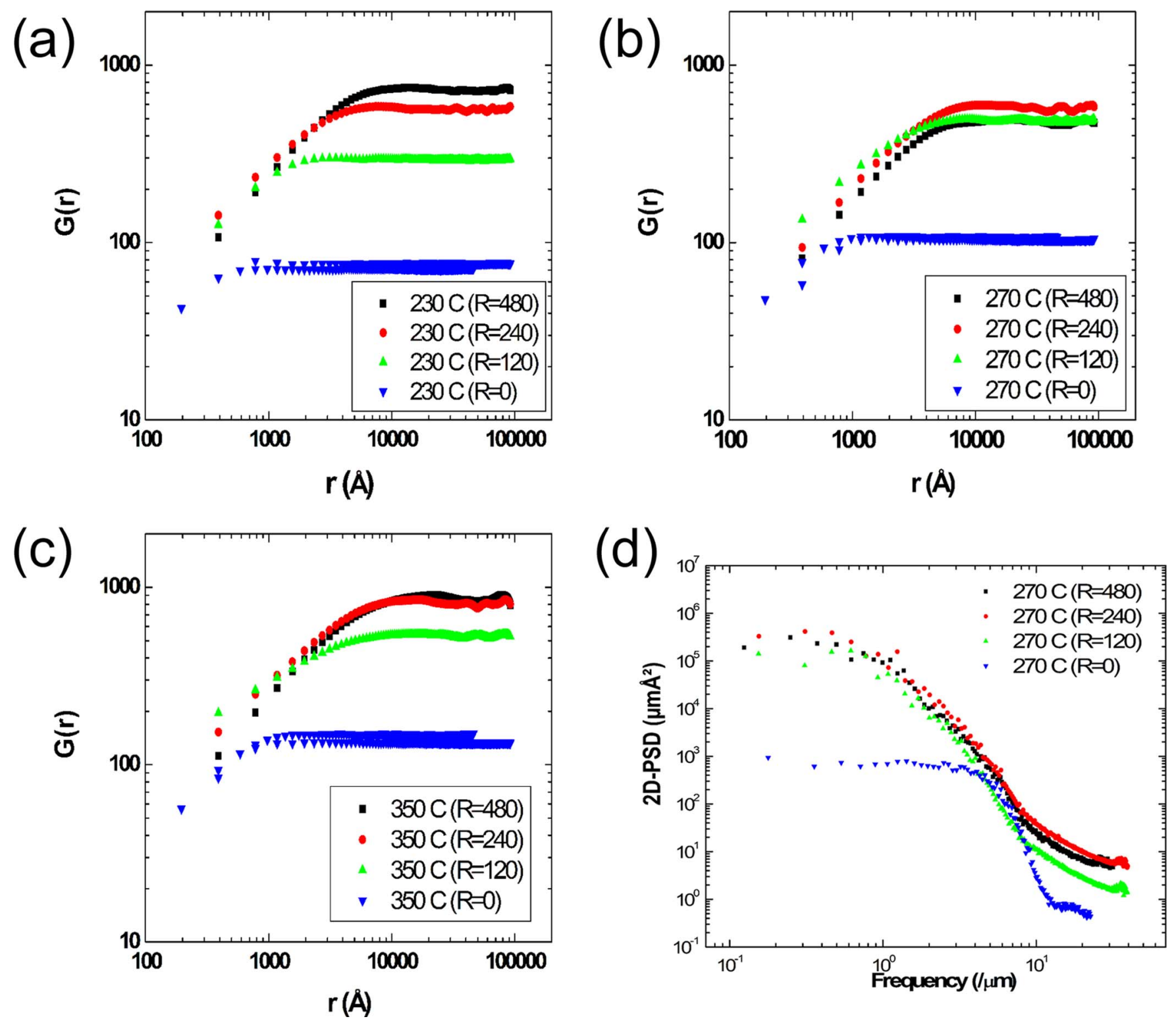

FIG. 4. (Color online) (a-c) Effect of dilution ratio $(R)$ and substrate temperature on height-height correlation function of Si thin films. The average film thickness is $300 \mathrm{~nm}$. (d) Representative PSD for films grown at $270{ }^{\circ} \mathrm{C}$.

height-height correlation function in Fig. 4 consists of two regimes, which are separated by the correlation length $\xi$. At length scale $r<\xi$, the slope of $G(r)$ increases as $G(r) \sim r^{\alpha}$, where $\alpha$ is the static scaling coefficient. At length scales much greater than $\xi$, the saturation rms value is reached and there is no further increase in $\sigma$ with increasing length scale. The rms value also increases with thickness as $\beta$, the dynamic scaling coefficient. The RMS roughness value and $\xi$ represent the vertical and lateral sizes of the mountains or valleys in the rough surface, respectively.

The static scaling coefficient is correlated to the local surface fractal dimension and is indicative of the surface texture in the short scaling range, $r<\xi{ }^{26}$ The static scaling coefficients in this series range from 0.42 to 0.86 (Fig. 5) and are associated with a local fractal dimension $D_{F}$, by the relation $D_{F}=3-\alpha$. The fractal dimensions obtained range from $D_{F}$ $=2.14-2.58$ and indicates that the surface roughens quickly, and one would expect $\mathrm{Si}$ to be the main deposition species due to its large sticking probability of $\sim 1$. Although $\mathrm{Si}$ is the most prevalent species desorbed from the wire, ${ }^{24,33,35}$ in this pressure and hydrogen dilution regime the predominant growth species should be $\mathrm{SiH}_{3}{ }^{34,35}$. $\mathrm{SiH}_{3}$ can also diffuse on a hydrogenated surface, like our Si (100) substrates at temperatures $350{ }^{\circ} \mathrm{C}$ and below, before being incorporated. ${ }^{36}$ This allows for a much smaller, but important smoothening effect on the deposition and is seen by the slope of the highfrequency portion of the power spectral density (PSD) function ranging from -3.67 at $R=120, \mathrm{Ts}=350{ }^{\circ} \mathrm{C}$ and above with the highest slopes at $R=0$. All of the slopes in the highfrequency region of the PSD are near -4 [Fig. 4(d)], which is the theoretical value normally associated with surface diffusion. ${ }^{2,37}$

The Schwoebel effect is the asymmetrical nature of the sticking coefficient of adatoms to steps and its consequences 


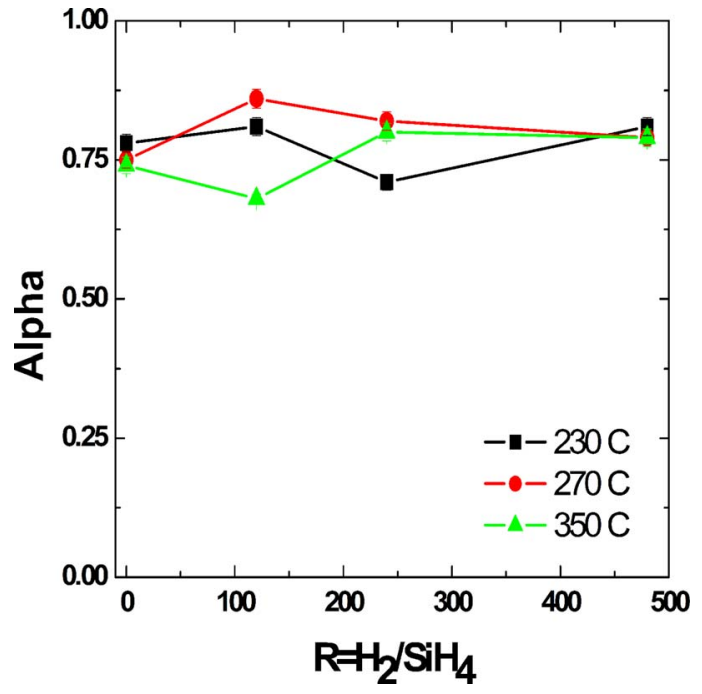

FIG. 5. (Color online) (a) Static scaling coefficient exponent $\alpha$ at different substrate temperatures as a function of hydrogen dilution.

on the surface evolution. A diffusing atom along an upper ledge sees a barrier, the Schwoebel energy barrier, toward going to a lower ledge. A positive Schwoebel effect causes the surface roughness to increase with deposition time. A

(a)

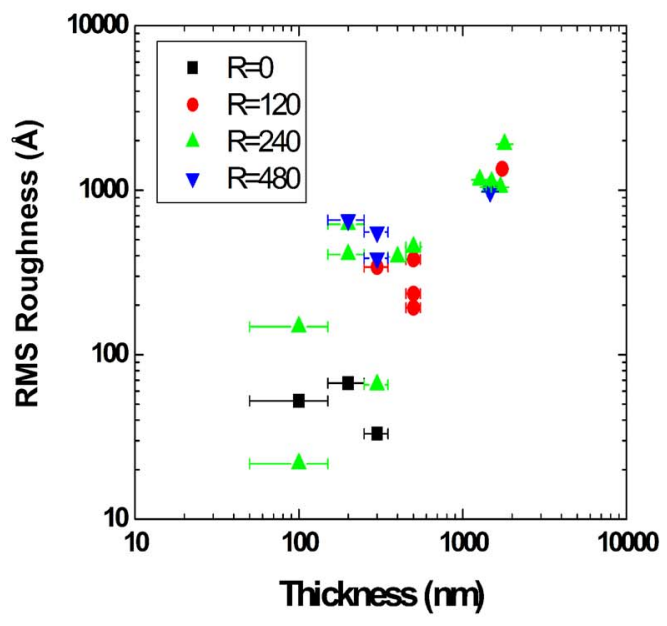

(c)

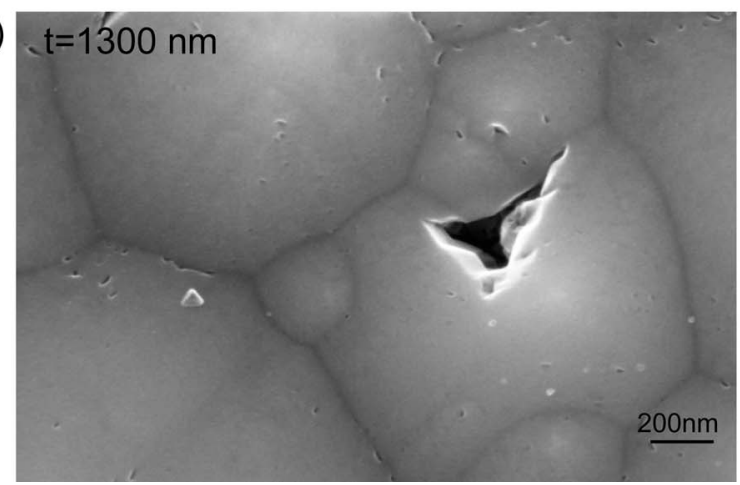

negative barrier would cause the surfaces to smoothen during growth. ${ }^{38}$ As shown in Fig. 1, the majority of these films are epitaxial, and so one would expect that most of the step edges and faces are in the $\langle 100\rangle$ directions. However, because these films are so rough, there are additional growth directions, presumably with each having a different Schwoebel barrier. ${ }^{39}$ We will not address the Schwoebel energy at each possible surface step, as this would be too complicated in our current system and would give little additional insight. Moreover, the surface diffusion effect is thought to be less important than the effect $\mathrm{H}$ etching in determining the surface roughness, as evidenced by the increase in roughness being more dependent on the $\mathrm{H}$ dilution than the substrate temperature.

However, this energy barrier is thought to be small and positive for most crystallographic directions found in silicon growth and would be consistent with the roughening of our surfaces during growth (Fig. 6). ${ }^{39}$ It is also possible that the roughness of these films does not allow the growth of [111] facets, typical during epitaxial growth by most other methods. This may also contribute to the breakdown of the epitaxial or twinned phase into a polycrystalline phase, rather than an amorphous phase. ${ }^{4,39}$

As mentioned earlier, there is a general increase in the saturated rms roughness with thickness (Fig. 6). These films are categorized by dilution, but for each dilution the films

(b)
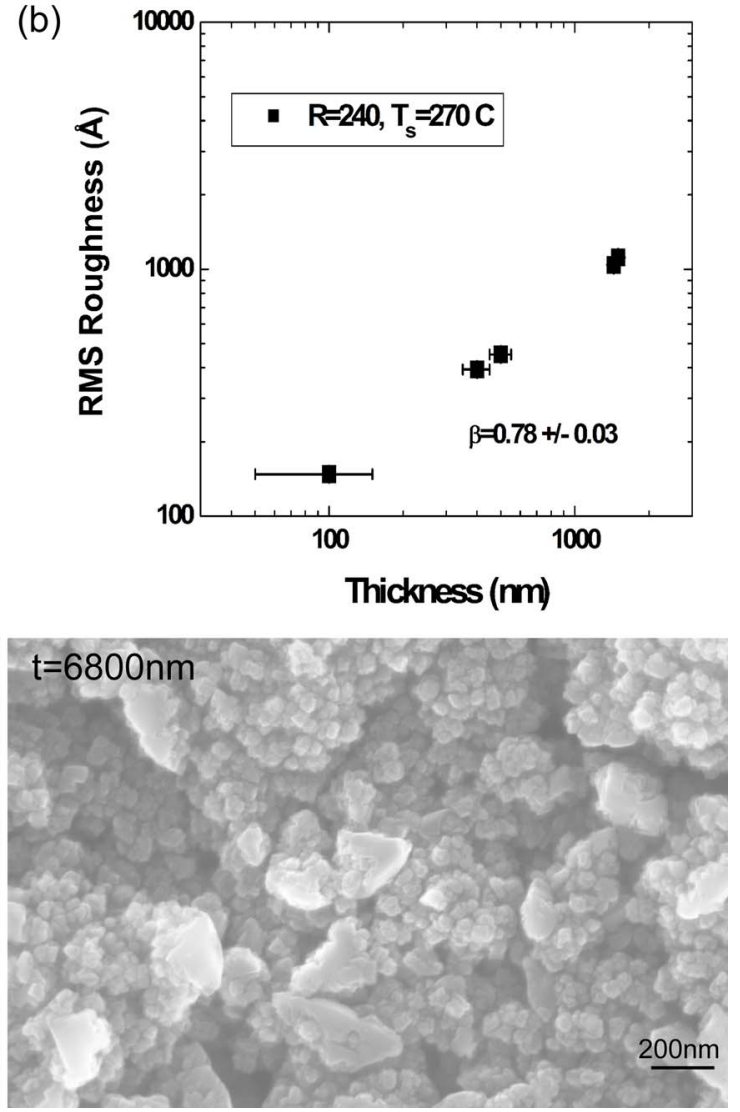

FIG. 6. (Color online) (a) The effect of thickness on rms roughness at several dilutions. Substrate temperatures vary from $230-350{ }^{\circ} \mathrm{C}$, pressures from 75-120 mTorr, wire to substrate spacings of $3.5-5 \mathrm{~cm}$, and wire temperatures from $1350-1550{ }^{\circ} \mathrm{C}$. (b) rms roughness as a function of thickness for films deposited at $R=240$ and $T_{s}=270{ }^{\circ} \mathrm{C}$ and $<1500 \mathrm{~nm}$. (c) SEM of the surface evolution of a film grown at $R=240, T_{s}=350{ }^{\circ} \mathrm{C}, 4.2 \mathrm{~cm}$ wire to substrate spacing, and $120 \mathrm{mTorr}$ at $1300 \mathrm{~nm}$ and $6800 \mathrm{~nm}$. 
were deposited under a range of substrate temperatures $\left(230-350{ }^{\circ} \mathrm{C}\right)$, pressures $(75-120 \mathrm{mTorr})$, wire to substrate distances $(3.5-5 \mathrm{~cm})$, and wire temperatures (1350$\left.1550{ }^{\circ} \mathrm{C}\right)$. The scatter in Fig. 6 reflects the wide range of deposition conditions. For example, the data for $R=240$ includes depositions at several experimental settings described above. The entire set of data at $R=240$ has a $\beta$ value of $0.82 \pm 0.20$ for $r<1500 \mathrm{~nm}$, while the subset of films grown at $270{ }^{\circ} \mathrm{C}$ and $R=240$ have a $\beta$ value of $0.78 \pm 0.03$ [Fig. 6(b)].

\section{DISCUSSION}

We suggest that aside from the thickness, under the deposition conditions described above, hydrogen dilution is the most important factor that determines the surface evolution of a HWCVD grown crystalline film. As a starting point, at $R=240$ and all substrate temperatures and deposition conditions, $\beta=0.82 \pm 0.20$ and $\alpha=0.78 \pm 0.06$. The high values of the static and dynamic scaling coefficients of these HWCVD grown films at $R=240$ are more akin to those observed in sputter deposition process, than in other CVD methods. ${ }^{1,22}$ Shadowing growth has been observed in sputtered amorphous silicon ${ }^{40}$ and modeled by Monte Carlo simulations ${ }^{21,41}$ with growth coefficients of $\beta=1$. For shadowing models, the morphology of neighboring points can result in shadowing where the valleys of the surface grow less than the hills around them despite the fact that there is an extended source. Relaxing this model to allow for surface diffusion, in the present case of $\mathrm{SiH}_{3}$, decreases the growth exponent $\beta$ to between 0.5 and 1 . This modified model fits well for the above data for $R=240$ and is confirmed by the SEM images in Fig. 2, where surface roughness is characterized by a bimodal feature size distribution indicating some porosity from a shadow growth. We suggest that this is due to a shadowed etch of the incoming $\mathrm{H}$ atoms, rather than a more traditional shadowed growth. This would also offer an explanation as to how epitaxial films not only grow rough, but are able to grow on such rough surfaces. Hydrogen could preferentially etch those atoms which are defects, and consequently at a lower bond energy, than those that are in the epitaxial structure.

By comparing the SEMs and rms roughness of Figs. 2 and 3 we conclude that a similar deposition mechanism must contribute to growth at $R=120$ and at $R=480$ as in $R=240$. At $R=120$, the rms roughness and correlation lengths are less than those at $R=240$, and there are additional smaller surface features. Because of the decrease in $\mathrm{H}$ available for etching defective adatoms under the $R=120$ regime as opposed to $R=240$, at low temperatures these films at $300 \mathrm{~nm}$ are twinned rather than epitaxial. Moreover, hydrogen etching of silicon is known to be less effective at higher temperatures, and thus at $350{ }^{\circ} \mathrm{C}$, the etching mechanism is insufficient to quench the polycrystalline breakdown of this film. Films with $R=120$ also had the highest deposition rates in this study of up to $5 \mathrm{~nm} / \mathrm{min}$, and thus, one would expect the dynamic scaling coefficient to be close to 1 .

As shown in Table I, the deposition rates of films grown at $R=0$ vs $R=480$ vary at most by a factor of 5 and do not increase monotonically as a function of silane partial pressure. Moreover, the morphology of an etched surface as in $R=120$ and 240 is not evident at $R=480$. This could mean that the deposition species come from another source aside from the precursors off the hot filament. One explanation for this is that at $R=480$, it is important to consider growth species reemission and deposition following the reemission model presented by Karabacak et al. who found experimentally $\beta=0.41$ and $\alpha=0.83 .^{40}$ In this model, each atom has a finite sticking probability depending on how many times it has been reemitted. ${ }^{42}$ Surface diffusion and a directional incident flux on the growing surface are also considered and are consistent with deposition conditions in the HWCVD experiments. The additional hydrogen is also thought to minimize the shadowing etch found at lower dilution, to a more universal etch and a deposition mechanism that is predominantly redeposition or reemission dominated, which with a high abstraction rate of $\mathrm{SiH}_{4}$ from $\mathrm{H}$ and $\mathrm{Si}$, is produced and available for redeposition. ${ }^{35,43}$ The redeposition of species usually occurs at peaks or crests on the surface. This would increase the film roughness quickly consistent with the observed large static and dynamic scaling coefficients.

It is also possible that the steady-state surface coverage of hydrogen limits reactive adsorption and thus is the growth limiting step in this study. ${ }^{44}$ In this case, the growth rate is determined by a balance between abstraction, desorption, and adsorption of hydrogen on the surface of the substrate. All of these effects are temperature dependent while the abstraction and adsorption of hydrogen are also hydrogen dilution dependent. Hydrogen abstraction should dominate at conditions of high hydrogen dilution.

In our growths the $\mathrm{H}$ etching or abstraction mechanism is thought to be extrememly important. Otobe et al..$^{45}$ found that the roughness of $\mathrm{H}$ etched $\mathrm{Si}$ increased with increasing substrate temperature, consistent with our results. Other possible explanations for the role of hydrogen have been put forth by a number of authors: Nakata et al. suggest that the atomic hydrogen coverage or the growing surface enables surface species to have a higher mobility, ${ }^{46}$ explaining the decrease in roughness with decreasing substrate temperature. Another possible mechanism at high dilutions is the chemical annealing effect. ${ }^{47,48}$ The chemical annealing mechanism has been used to explain the low-temperature crystallization of silicon ${ }^{48}$ by the insertion of $\mathrm{H}$ atoms into the strained $\mathrm{Si}-\mathrm{Si}$ bonds. ${ }^{49}$ The subsequent relaxation of the bonds as the $\mathrm{H}$ diffuses through results in the crystallization of the structure. The hydrogen content of our films is found to increase with increasing temperature at a given dilution and to increase with increasing dilution at a given temperature so that films with more $\mathrm{H}$ incorporation appear to have a larger rms roughness similar to results by Jo et al. for the direct absorption of atomic hydrogen in $\mathrm{Si}(100) .^{50}$ However, there is no immediate correlation of hydrogen content with structure as our films become more epitaxial at higher dilutions and lower substrate temperatures.

Although the specific growth mechanism cannot be determined through ex situ surface studies, given the surface morphology analysis and the fact that the growth rate and the flux of growth species are approximately the same under all discussed growth conditions hydrogen appears to be the pre- 
dominant species in determining the growth regime of HWCVD grown crystalline Si films. At zero hydrogen dilution $(R=0)$, growth is primarily due to the species coming from the wire. At midrange dilutions $(R=120-240)$, growth is still mainly from the wire, but a shadow dominated etch occurs simultaneous with growth which roughens the deposition surface. At the highest hydrogen dilutions $(R=480)$, it is possible that the growth is dominated by redeposition of previously $\mathrm{H}$-abstracted and desorbed surface species; i.e., we suggest that at high $R$, most growth species have been "recycled" through the sequence of growth $\rightarrow$ abstraction $\rightarrow$ desorption $\rightarrow$ redeposition more than once. The high hydrogen dilution provides a unique deposition environment and growth regime for epitaxial films to grow on rough surfaces.

\section{CONCLUSIONS}

We have shown that rms roughness increases with increasing substrate temperature and with increasing dilution ratio for crystalline silicon films on silicon substrates. This is similar to the trend seen in amorphous films, but not in other crystalline systems, particularly in the high $\mathrm{H}$ dilution regime. This trend is due to the large amount of atomic hydrogen involved in the HWCVD process and allows epitaxial growth to continue even on the roughest surfaces. Hydrogen dilution is thus found to be the most important determinant of the growth regime. Films grown without additional hydrogen grow in the random deposition with relaxation regime, while increasing hydrogen leads to shadowing and finally the etching and reemission growth regime.

\section{ACKNOWLEDGMENTS}

The authors would like to thank Melissa Griggs for the height-height correlation function code and Liz Miura for Raman measurements. We also thank BP Solar and the National Renewable Energy Laboratory for their support of this project, and C.E.R. would like to thank Corning Inc. through the NPSC for their financial support.
*Corresponding author. E-mail address: cesber@caltech.edu

${ }^{1}$ A. H. M. Smets, W. M. M. Kessels, and M. C. M. van de Sanden, Appl. Phys. Lett. 82, 865 (2002).

${ }^{2}$ K. R. Bray and G. N. Parsons, Phys. Rev. B 65, 035311 (2001).

${ }^{3}$ D. M. Tanenbaum, A. L. Laracuente, and A. Gallagher, Phys. Rev. B 56, 4243 (1997).

${ }^{4}$ D. J. Eaglesham, J. Appl. Phys. 77, 3597 (1995).

${ }^{5}$ M. V. R. Murty, Ph.D. thesis, California Institute of Technology, 1994.

${ }^{6}$ N.-E. Lee, D. G. Cahill, and J. E. Greene, Phys. Rev. B 53, 7876 (1996).

${ }^{7}$ M. S. Mason, Ph.D. thesis, California Institute of Technology, 2004.

${ }^{8}$ C. E. Richardson, M. S. Mason, and H. A. Atwater, Mater. Res. Soc. Symp. Proc. 808, A8.11 (2004).

${ }^{9}$ C. W. Teplin, E. Iwaniczko, K. M. Jones, R. Reedy, B. To, and H. M. Branz, Mater. Res. Soc. Symp. Proc. 862, A2.3 (2005).

${ }^{10}$ J. K. Holt, M. Swiatek, D. G. Goodwin, R. P. Muller, W. A. Goddard III, and H. A. Atwater, Thin Solid Films 395, 29 (2001).

${ }^{11}$ R. E. I. Schropp, K. F. Feenstra, E. C. Molenbroek, H. Meiling, and J. K. Rath, Philos. Mag. B 76, 309 (1997).

${ }^{12}$ R. E. I. Schropp, Thin Solid Films 451-452, 455 (2004).

${ }^{13}$ C. E. Richardson, M. S. Mason, and H. A. Atwater, Proceedings of 31st IEEE PVSC, Lake Buena Vista, Fl, 2005.

${ }^{14}$ E. C. Molenbroek, A. H. Mahan, E. J. Johnson, and A. C. Gallagher, J. Appl. Phys. 79, 7278 (1996).

${ }^{15}$ H. R. Moutinho, C.-S. Jiang, J. Perkins, Y. Xu, B. P. Nelson, K. M. Jones, M. J. Romero, and M. M. Al-Jassim, Thin Solid Films 430, 135 (2003).

${ }^{16}$ J. Robertson, J. Appl. Phys. 93, 731 (2003).

${ }^{17}$ C. E. Richardson, M. S. Mason, and H. A. Atwater, Thin Solid Films 501, 332 (2006).

${ }^{18}$ R. Bruggemann and F. Houze, Proceedings of 16th European Photovoltaic Solar Energy Conference, Glasgow, 2000.
${ }^{19}$ D. Levi, B. Nelson, J. Perkins, and H. Moutinho, NCPV Program Review Meeting, Lakewood, CO, 2001.

${ }^{20}$ D. J. Eaglesham, F. C. Unterwald, H. Luftman, D. P. Adams, and S. M. Yalisove, J. Appl. Phys. 74, 6815 (1993).

${ }^{21}$ J. T. Drotar, Y.-P. Zhao, T.-M. Lu, and G.-C. Wang, Phys. Rev. B 62, 2118 (2000).

${ }^{22}$ F. Family, J. Phys. A 19, L441 (1986).

${ }^{23}$ G. S. Bales, A. C. Redfield, and A. Zangwill, Phys. Rev. Lett. 62, 776 (1989); D. D. Vvedensky, A. Zangwill, C. N. Luse, and M. R. Wilby, Phys. Rev. E 48, 852 (1993); C. M. Horowitz, R. A. Monetti, and E. V. Albano, ibid. 63, 066132 (2001); A. Mazor, D. J. Srolovitz, P. S. Hagan, and B. G. Bukiet, Phys, Phys. Rev. Lett. 60, 424 (1988).

${ }^{24}$ J. Yu and J. G. Amar, Phys. Rev. E 65, 060601(R) (2002).

${ }^{25}$ F. Family and T. Vicsek, J. Phys. A 18, L75 (1985).

${ }^{26}$ V. Constantoudis, G. P. Patsis, A. Tserepi, and E. Gogolides, J. Vac. Sci. Technol. B 21, 1019 (2003).

${ }^{27}$ F. Finger, R. Carius, T. Dylla, S. Klein, S. Okur, and M. Gunes, J. Optoelectron. Adv. Mater. 7(1), 83 (2005).

${ }^{28}$ S. Gupta, G. Morell, and B. R. Weiner, J. Non-Cryst. Solids 343, 131 (2004).

${ }^{29}$ G. Ganguly and A. Matsuda, Phys. Rev. B 47, 3661 (1993).

${ }^{30}$ M. Fehrenbacher, J. Spitzmuller, M. Pitter, H. Rauscher, and R. J. Behm, Jpn. J. Appl. Phys., Part 1 36, 3804 (1997).

${ }^{31}$ K. Sasaki and T. Takada, Jpn. J. Appl. Phys., Part 1 37, 402 (1998).

${ }^{32}$ O. P. Karpenko, S. M. Yalisove, and D. J. Eaglesham, J. Appl. Phys. 82, 1157 (1997).

${ }^{33}$ J. J. C. Doyle, J. Appl. Phys. 64(6), 3215 (1988); S. Tange, K. Inoue, K. Tonokura, and M. Koshi, Thin Solid Films 395, 42 (2001).

${ }^{34}$ A. Gallagher, Thin Solid Films 395, 25 (2001).

${ }^{35}$ J. K. Holt, Ph.D. thesis, California Institute of Technology, 2003.

${ }^{36}$ T. Karabacak, Y. P. Zhao, G. C. Wang, and T. M. Lu, Phys. Rev. B 66, 075329 (2002) 
${ }^{37}$ B. A. Sperling and J. R. Abelson, Appl. Phys. Lett. 85, 3456 (2004).

${ }^{38}$ J. Villain and I. Elkinant, J. Phys. I 4, 949 (1994).

${ }^{39}$ T. A. Wagner, Ph.D. thesis, University of Stuttgart, 2003.

${ }^{40}$ T. Karabacak, Y.-P. Zhao, G.-C. Wang, and T.-M. Lu, Phys. Rev. B 64, 085323 (2001).

${ }^{41}$ J. H. Yao and H. Guo, Phys. Rev. E 47, 1007 (1993).

${ }^{42}$ J. T. Drotar, Y.-P. Zhao, T.-M. Lu, and G.-C. Wang, Phys. Rev. B 61, 3012 (2000).

${ }^{43}$ A. Masuda, K. Kamesaki, A. Izumi, and H. Matsumura, Mater. Res. Soc. Symp. Proc. 664, A4.5 (2001).

${ }^{44}$ K. Werner, S. Butzke, S. Radelaar, and P. Balk, J. Cryst. Growth 136, 338 (1994).

${ }^{45}$ M. Otobe, M. Kimura, and S. Oda, Jpn. J. Appl. Phys., Part 1 33,
4442 (1994).

${ }^{46}$ M. Nakata, A. Sakai, T. Uematsu, T. Namikawa, H. Shirai, J.-I. Hanna, and I. Shimizu, Philos. Mag. B 63, 87 (1991); P. Reinig, F. Fenske, B. Selle, W. Bohne, J. Rohrich, I. Sieber, and W. Fuhs, Appl. Surf. Sci. 227, 114 (2004).

${ }^{47}$ K. Nakamura, K. Yoshino, S. Takeoka, and I. Shimizu, Jpn. J. Appl. Phys., Part 1 34, 442 (1995).

${ }^{48}$ H. Shirai, D. Das, J.-I. Hanna, and I. Shimizu, Appl. Phys. Lett. 59, 1096 (1991).

${ }^{49}$ S. Sriraman, S. Argarwal, E. S. Aydil, and D. Maroudas, Nature (London) 418, 62 (2002).

${ }^{50}$ S. K. Jo, J. H. Kang, X.-M. Yan, J. M. White, J. G. Ekerdt, J. W. Keto, and J. Lee, Phys. Rev. Lett. 85, 2144 (2000).

${ }^{51}$ C. E. Richardson (unpublished). 